\title{
SURGICAL MANAGEMENT OF OPHTHALMIC TRAUMA DUE TO THE PALESTINIAN INTIFADA
}

\author{
ZIAD M. JAOUNI and JOHN G. O'SHEA \\ East Jerusalem
}

\section{SUMMARY}

Purpose: The purpose of the study was to determine the causes, morbidity and visual outcome of 567 Intifada eye injuries which occurred during a 6 year period from December 1987 to December 1993.

Methods: A prospective study was undertaken of Intifada eye injuries from December 1987 to December 1993 which were treated at the St John Ophthalmic Hospital, Jerusalem, or in private clinics in East Jerusalem, the West Bank and Gaza.

Results: Seventy-five per cent of those injured came from East Jerusalem or the West Bank. The average age of a person injured was 17 years. Male preponderance was $84.7 \%$. The study demonstrates both the high morbidity and the poor visual outcome which characterise Intifada eye injuries. There were 567 eyes in the series, of which $143(25.2 \%)$ lost perception of light and $72(12.6 \%)$ had vision less than or equal to $6 / 60$. Eighty-six eyes (15.1\%) required enucleation. In total 43.1\% of the series had severe ocular injuries. Rubber or plastic bullets caused 154 injuries. They were the commonest indication for the enucleation of an eye (90.6\% of 86 enucleations). There were 3 cases of severe Gram-negative endophthalmitis in the group of patients who presented late to the hospital $(0.52 \%)$.

Conclusions: Intifada injuries are associated with far greater morbidity than non-military eye injuries. Rubber or plastic bullet injuries are the leading cause of visual loss and of eye enucleation. Military curfews exacerbate the morbidity of Intifada injuries by prolonging evacuation time.

St John has operated an ophthalmic hospital in the Holy Land since 1882. The hospital is sited at Sheikh Jarrah, East Jerusalem. This paper records injuries due to the Intifada between 1987 and 1993. The study is designed to delineate the morbidity of Intifada ophthalmic injuries.

Correspondence to: Z. M. Jaouni, MB BCh, DO, St John Ophthalmic Hospital, PO Box 19960, East Jerusalem 97200. Fax: 00972-2-5828327. e-mail: stjohn@palnet.com.

\section{METHOD}

A prospective study was made of all eye injuries relating to the Intifada by ophthalmologists working from the St John Ophthalmic hospital and in private clinics in Jerusalem between 1987 and 1993. A Claris Works 1.0 Spreadsheet/Data Base was used to record injuries and their prognosis. The mechanism of injury was recorded along with operative findings and the final visual acuity.

\section{RESULTS}

The 567 eye injuries in the series were recorded between 1987 and 1993. Seventy-five per cent of patients came from East Jerusalem and the West Bank. The injuries at Gaza were more often associated with serious systemic injury and therefore the patients went to general hospitals. Secondly Gaza is frequently isolated from the St John Ophthalmic Hospital in East Jerusalem by the military curfews.

This series of eye injuries is typical of the light and intermediate casualties which are seen in civil conflict (Fig. 1).

\section{Age and Sex Distribution}

There is a high male preponderance, female injury constituting only $15.3 \%$ of the series.

The youngest patient was 2 months old. One female infant, aged 18 months, had to have her right eye eviscerated because of a rubber bullet injury and also received a compound orbital fracture. The mean age of the population studied was 17 years. It is the very young, the elderly and those who are less mobile who frequently suffer high-velocity missile injuries.

The year when most injuries occurred was 1989, during which there were 199 cases of ophthalmic trauma $(35 \%$ of total) compared with 10 cases reported in $1993(\sim 1.7 \%)$.

In a previous paper, which discussed international legal and political issues arising from Intifada eye injuries, the authors presented a detailed, tabulated 


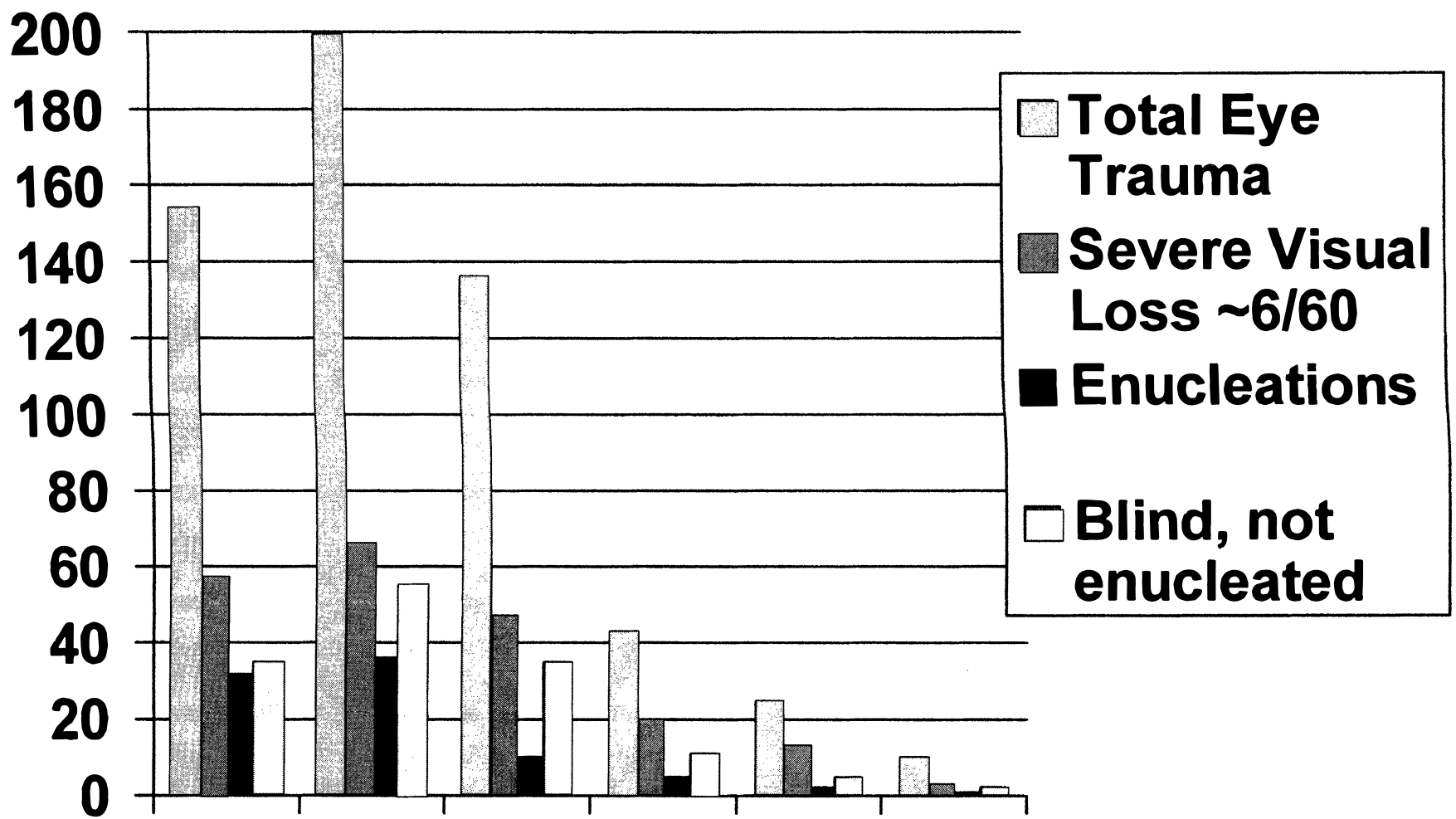

\section{7-8 $1990 \quad 1992$}

Fig. 1. Graphical summary of Intifada eye trauma, December 1989-1993.

summary of the mechanism of injury and the circumstances surrounding many of the injuries. ${ }^{1}$

\section{Severe Eye Injury (Table I)}

In this series the term 'serious' is used for injuries with a poor visual outcome, which is equated with those whose visual acuity falls below or equal to $6 / 60$. Most patients who had long-term visual disability had the mechanism of injury recorded; in some the final acuity was better than $6 / 60$.

\section{Rubber Bullet Injuries (Tables II, III)}

The commonest cause of the loss of an eye or of vision was rubber or plastic bullet injury, as direct impact will irreparably disrupt a globe. There were 154 rubber bullet injuries in this series Rubber

Table I. Overview of severe intifada ophthalmic injuries

\begin{tabular}{lcrrrrr}
\hline & Dec. 1987-8 & 1989 & 1990 & 1991 & 1992 & 1993 \\
\hline Total & 154 & 199 & 136 & 43 & 25 & 10 \\
Blind eyes & 35 & 55 & 35 & 11 & 5 & 2 \\
Enucleations & 32 & 36 & 10 & 3 & 2 & 1 \\
Vision $\sim 6 / 60$ & 31 & 55 & 35 & 11 & 5 & 2 \\
\hline
\end{tabular}

Table II. Tabulated total of paediatric injuries (children below 12 years)

\begin{tabular}{lcrcccc}
\hline & Dec $1987-8$ & 1989 & 1990 & 1991 & 1992 & 1993 \\
\hline Total & 27 & 20 & 9 & 5 & 1 & 0 \\
Males & 16 & 14 & 5 & 4 & 1 & 0 \\
Females & 11 & 6 & 4 & 1 & 0 & 0 \\
\hline
\end{tabular}

bullets in Israel are fired from multiple dispensers, are $20 \mathrm{~mm}$ in diameter and weigh $25 \mathrm{~g}$. Such projectiles due to their shape, velocity and size cause profound damage to the eye and orbit. The $37 \mathrm{~mm}$ baton type rubber or plastic bullet used in South Africa and Northern Ireland was used during the early years of the Intifada. Its use has been largely superseded by the spherical type, which has a higher rate of fire but a lower safety margin, especially with regard to ocular injuries.

These projectiles have been found in the maxillary sinuses and anterior cranial fossa. Maxillary sinus injury is the more common since soldiers usually fire from positions above the crowd. They can also penetrate the occipital bone at close range and one was removed from the posterior cranial fossa by neurological surgeons at the Maquassad Hospital, Jerusalem. In young children these projectiles are often associated with compound fractures of the orbit. Twelve of 30 children with rubber bullet injuries had compound fractures.

The possibility of sympathetic ophthalmia exists with these injuries.

Table III. Rubber/plastic bullet injuries tabulated

\begin{tabular}{lcrrrrc}
\hline & Dec $1987-8$ & 1989 & 1990 & 1991 & 1992 & 1993 \\
\hline Total & 45 & 49 & 36 & 11 & 9 & 4 \\
Males & 38 & 40 & 31 & 9 & 9 & 4 \\
Females & 7 & 9 & 5 & 2 & 0 & 0 \\
\hline
\end{tabular}


Table 4. Injury with live bullets

\begin{tabular}{lcccccc}
\hline & Dec $1987-8$ & 1989 & 1990 & 1991 & 1992 & 1993 \\
\hline Total & 9 & 6 & 2 & 1 & 0 & 0 \\
Males & 8 & 5 & 2 & 1 & 0 & 0 \\
Females & 1 & 1 & 0 & 0 & 0 & 0 \\
\hline
\end{tabular}

\section{Live Bullets (Table II)}

Live bullet injuries were invariably profound. For example, one man lost an eye due to live bullet injury. The projectile severed the contralateral optic nerve resulting in total blindness. Military combat type ammunition, which fragments upon impact, caused very profound injuries. The nature of injuries caused by this type of ammunition have previously been documented by Hunter. ${ }^{2}$

\section{Explosive Devices}

Explosive injuries were due to various types of military hardware. Small children who play with and collect the ammunition and military hardware left behind when troops bivouac near Arabic villages are often injured. In our series 4 children received severe injuries in this way. Patients have also been injured by landmines. Explosive injuries are often bilateral. In total 11 people were injured by explosives. Two patients had a type of adult-acquired buphthalmos due to explosion barotrauma.

\section{The Visual Prognosis of Intifada Injuries}

A consistently high proportion of our patients had severe ocular problems, with retained vision less than or equal to 6/60. For example, in 1987-8, 79 of 154 cases $(51 \%)$ had severe visual loss, and in 1992-3, 4 of 10 cases $(40 \%)$.

\section{Miscellaneous Forms of Injury}

Gas canisters thrown either by hand or fired from propulsive devices mounted on automatic rifles cause injuries. There were chemical injuries due to tear gas. Some caused permanent eye damage.

\section{Direct Physical Confrontation}

Many eye injuries occur in the context of physical confrontation. Stoning often resulted in severe eye injury.

\section{Summary of Results}

Eye injury resulted from a wide variety of disparate mechanisms. A high proportion of casualties required intensive surgical intervention. In Intifada confrontations many bystanders, particularly children or the elderly or immobile, are injured.

\section{DISCUSSION}

The Intifada is the colloquial name given to the Palestinian uprising. The word is derived from an Arabic verb meaning 'to shake off'. ${ }^{1-3}$ It has been studied extensively from many perspectives by journalists, academics and lawyers in the Middle East and in the West. ${ }^{2-4}$ The beginning of the conflict is dated to 8 December 1987 after a motor vehicle collision in Gaza. ${ }^{2,3}$ Our series begins at this time. ${ }^{1}$ Seventy-five per cent of patients came from East Jerusalem and the West Bank. Many injuries also occurred in Gaza, which is under-represented in this series.

In his published series of 11 penetrating eye injuries in West Bank children due to rubber bullets, Elder notes the poor prognosis of the injury. ${ }^{4}$ The mean age of his patients was 11.1 years (range 13-17 years) and 9 of these patients eventually had no perception of light. Six patients required enucleation as a primary procedure; two required secondary enucleation. Elder notes that sympathetic ophthalmia, and therefore the possibility of blindness, could occur in connection with these injuries. This would be especially likely if patients were denied access to specialist ophthalmic care. Elder estimates that $14 \%$ of penetrating eye injuries in children are due to the Intifada. He also estimates the incidence of penetrating injury on the West Bank to be 4.0 per 100000 , though this may be an underestimate. Elder esti-

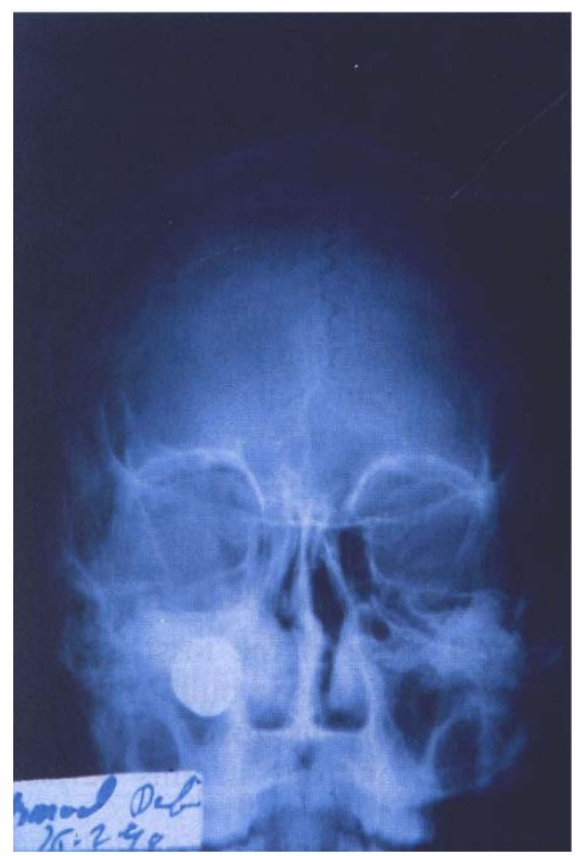

Fig. 2. A plastic bullet embedded in the right maxillary sinus. This injury to a 21-year-old man was sustained on 26 February 1996 at the Al'Aqsa Mosque, Jerusalem. The fighting at the mosque was in response to an incident where many Palestinians were killed at the cave of the Patriachs, Hebron. The $20 \mathrm{~mm}$ spheroidal projectiles cause gross ocular and orbital damage. The projectile was fired from above and its trajectory was through the orbit disrupting the globe and thence through the orbital plate of maxillary bone and into the sinus. The right eye was enucleated and open sinus surgery undertaken to remove the projectille. The projectiles are fired from semi-automatic dispensers; low ballistic accuracy may contribute to the high injury rate. 
mates that $75 \%$ of these injuries are seen at the St John Ophthalmic Hospital.

\section{Rubber and Plastic Bullets}

As rubber and plastic bullets are the principal cause of ocular morbidity due to the Intifada, detailed discussion of their effects is warranted.

There are several types of rubber bullets used by the security forces. Elder notes the use of the bullets for crowd control. The commonest type weighs $25 \mathrm{~g}$ and may penetrate the skull if fired at close range. The spherical projectiles are about $20 \mathrm{~mm}$ in diameter and enter the orbit readily, grossly disrupting the soft tissues of the orbit and not uncommonly causing fractures of the orbital bones. ${ }^{5}$

The muzzle velocity is $240 \mathrm{~m} / \mathrm{s}^{5}$ We found projectiles in the maxillary sinus. Balouris ${ }^{6}$ notes that the security forces use both rubber and plastic bullets which are often fired from multiple dispensers attached to automatic rifles. This type of rubber bullet is quite different from those used in South Africa $^{7}$ and in Northern Ireland, ${ }^{8.9}$ which are characteristically of the baton type. The small, spherical projectiles associated with our series cause severe damage to the eye and orbit. The baton type does not penetrate as readily and is ballistically more accurate.

Compound fractures of the orbit are not uncommon in relation to rubber or plastic bullet injury. Balouris $^{6}$ noted 10 fractures in his series of 69 patients. His findings on the morbidity of rubber bullets are reproduced for comparison with our own: ruptured globe (36), hyphaema (15), orbital fracture (10), posterior segment commotio (4) and intraocular foreign body (1). Our results are thus consistent with these previous findings - a high proportion of very serious ocular injuries not infrequently resulting in enucleation or visual loss.

The design of the projectile influences the type of injury sustained. Rubber bullets which caused severe injuries to the face and skull were abandoned in Northern Ireland and replaced by plastic bullets. Both Cohen ${ }^{7}$ and Rocke ${ }^{8}$ noted the potential of both types of projectile to cause serious injuries to the skull. The small spherical projectiles in use in Israel infrequently lodge themselves in the orbit (Fig. 2). The mortality of rubber bullets is estimated as 1/ 16000 rounds fired and that of plastic bullets $1 / 4000$ rounds fired. ${ }^{9}$

With regard to possible changes induced in the posterior segment Atmaca and Yilma ${ }^{10}$ investigated changes in the fundus due to blunt ocular trauma in relation to patient age and sex and the cause of the trauma. Included in this study were the 445 patients who applied to the Eye Clinic of the Faculty of Medicine, Ankara University because of blunt eye trauma, together with patients from private practice, during the period 1980 to 1991 . The changes detected in the 445 eyes included in this study were: retinal detachment (194), retinal and choroidal atrophy (52), vitreous haemorrhage (50), optic atrophy (43), Berlin's oedema (42), choroidal rupture (36), macular hole (18), macular haemorrhage (16), retinal hole (9), papillary-macular membrane (8), arterial occlusion (7), avulsion of the optic nerve (5) and retinalpapillary oedema $(3) .^{10}$

\section{Evacuation of Casualties}

Balouris noted that of 35 patients attending St John Ophthalmic Hospital, only 9 were seen within 24 hours of the injury. This tardy presentation continues to be a feature of the Intifada. The problem is caused by both transportation difficulties and military curfews. ${ }^{1,6}$

\section{Population Characteristics}

Much of the morbidity of the Intifada falls upon the young and the poorly mobile. As noted, a high proportion of injuries occur in the young and in children. These are more likely to be the children of the socio-economically deprived or of refugees $(72 \%)^{1}$

\section{Management Policy for Intifada Patients at St John Ophthalmic Hospital}

Antibiotics and Infection. All patients with penetrating injuries receive topical and intravenous antibiotics and prompt surgical attention. Aminoglycoside antibiotic cover is important because of a high incidence of gram-negative intraocular infection. Gentamicin is given in combination with a thirdgeneration cephalosporin, usually cefuroxime (ciprofloxacin is not available in Jerusalem.) Tetanus prophylaxis is also given as required.

Risk Factors for Endophthalmitis. Gram-negative endophthalmitis of a severe nature is a not uncommon problem in our patients, delay in presentation being the most important risk factor for developing exogenous endophthalmitis. Three patients had gram-negative endophthalmitis documented microbiologically, one had a Proteus infection and two had a Pseudomonas infection. One eye required evisceration. Two eyes were retained but became sightless and phthisical. Foreign bodies are also associated with an increased risk of infection and are also a tetanus risk.

Enucleation. Where possible eyes are spared, but often primary enucleation with debridement is a necessity because of retained intraocular and intraorbital foreign bodies. Not uncommonly scleral tears extend behind the equator and there is herniation of uveal tract tissue into the orbit. The globe is often grossly deformed by the impact of the projectile. 
Such eyes are often enucleated to prevent sympathetic ophthalmia. The visual prognosis if such eyes are not enucleated is extremely poor. Enucleation also improves cosmesis, as most eyes eventually become red and phthisical. They may also be painful due to bullous keratopathy.

Enucleated eyes commonly receive an orbital implant, usually of the acrylic ball or Castroviejo type, although we are now beginning to fit hydroxyapatite ball implants. There is now a resident ocularist at St John who has fitted over 130 Intifada patients with artificial eyes. Sixty lost their eyes due to rubber bullets and she privately fitted 64 patients from Gaza who had live bullet injuries. Six patients in her series lost their eyes due to explosive devices. Her management includes the psychological counselling of these patients. ${ }^{11}$

\section{Acquired Buphthalmos in Adults Due to Explosive Injury}

Two adult male patients who had explosive injuries developed a disfiguring, acquired buphthalmos due to traumatic angle and scleral damage.

\section{Morbidity of Non-Military versus Military Injuries in this Region}

Intifada ophthalmic injuries characteristically have an inordinately high associated morbidity. Of the 69 injuries Balouris ${ }^{6}$ saw in a 21 -month period at the St John Ophthalmic Hospital (December 1987-September 1989), required operation and 29 required enucleation. Jaouni's ${ }^{1}$ more comprehensive series of patients, which includes private patients, reflects similar, severe morbidity. By contrast only $2 \%$ of penetrating injury in Israel not associated with the Intifada required enucleation and the surgical results of non-military eye injury at St John are consistent with the results of this survey. ${ }^{12}$ It is stressed that this difference is due to the severe nature of the injuries we see. ${ }^{1}$

\section{The Epidemiology of Ocular Trauma in Other Communities}

Reviewing non-military trauma, Thylefors ${ }^{13}$ notes that ocular trauma is the cause of blindness in approximately half a million people worldwide, and many more have suffered partial loss of sight. Trauma is often the most important cause of unilateral loss of vision in developing countries. There is a cumulative risk of ocular trauma and visual loss during life, but the true incidence of accidents involving the eyes is not known. Males tend to have more eye trauma than females, and this is already apparent from childhood; lower socioeconomic classes are also more associated with ocular trauma. The setting for the occurrence of nonmilitary trauma is most commonly the workplace and, increasingly, road accidents. The impact of ocular trauma, in terms of need for medical care, loss of income and cost of rehabilitation services when indicated, clearly makes the strengthening of preventive measures very worthwhile.

The National Eye Trauma System Registry (USA) cumulated data on the aetiology and outcome of eye trauma from 1985 to 1991 at 48 collaborating eye trauma centres in 28 States and Washington, DC. Eighty-three per cent of the cases involved men; the median age of the patients was 27 years, ranging from 1 to 92 years of age. Seventy-seven per cent of the injuries were unintentional, $22 \%$ were the result of assault, and $1 \%$ were self-inflicted. ${ }^{14}$ In $62 \%$ of the cases studied, the injured person's initial best corrected visual acuity in the injured eye was the ability to perceive hand motion, or worse. The settings in which the injuries occurred included the home $(28 \%)$, the workplace $(21 \%)$, at recreation $(11 \%)$, and in transportation $(8 \%)$. At the time of the injury, $1.5 \%$ of the injured persons were wearing safety glasses and $2.9 \%$ were wearing non-safety glasses. ${ }^{14}$ There was evidence of definite or possible alcohol use by at least $24 \%$ of the injured persons and of illicit drug use by $8 \%$. The most frequent types of tissue damage included corneal or scleral laceration, traumatic cataract, intraocular foreign body, vitreous haemorrhage, and prolapse of intraocular tissue.

Dannenberg et al. ${ }^{15}$ reviewed 648 cases of assaultrelated penetrating ocular injury reported to the National Eye Trauma System Registry from 1985 to 1991. They examined the circumstances surrounding and initial clinical findings in this case series. Eightythree per cent of the patients were male. The median age was 28 years; $77 \%$ were younger than age 40 years, and $17 \%$ were younger than age 20 years. The ocular injury was part of multiple trauma in $34 \%$ of cases. There was evidence of alcohol and illicit drug use by at least $48 \%$ and $6 \%$ of the injured persons, respectively. Seventeen per cent of the injuries involved powder or non-powder firearms. Fists, glass fragments, metal rods or pipes, knives and scissors were among the other objects causing injury. Posterior segment trauma, which occurred in $70 \%$ of cases, included vitreous haemorrhage ( $40 \%$ of cases), retinal detachment $(11 \%)$, presence of intraocular foreign bodies $(6 \%)$ and optic nerve damage $(4 \%)$. The initial visual acuity after injury was hand motion or worse in $74 \%$ of the cases. The authors concluded that strategies to prevent such injuries should focus on the origins of violence in general and are more difficult to devise than strategies to prevent eye injuries in other settings. Public health efforts to reduce the use of alcohol, drugs and firearms may reduce the incidence of these injuries. 


\section{SUMMARY AND RECOMMENDATIONS}

The majority of severe injuries associated with the Intifada occurred during the early years of the confrontation. The security forces later improved their approach to the management of civil unrest. This was in part due to a change in public opinion towards the Palestinians occurring after an incident on the Temple Mount in Jerusalem in 1990. The Intifada also moved into a phase which was less confrontational and more political in profile; it may be cautiously said that relations between the two communities may improve if this trend continues. ${ }^{2-4}$

The use of rubber or plastic bullets is now the leading cause of Intifada morbidity. ${ }^{1}$ The characteristics of the spherical projectiles in use predispose to severe ophthalmic trauma.

The frequent curfews which isolate the West Bank and Gaza Strip from medical services in East Jerusalem add to the morbidity of Intifada injury. Evacuation time greatly affects the outcome of the surgical management of injuries in the situation of war, accident or civil conflict ${ }^{16}$ and one would wish to see patients earlier if outcome is to be improved. To this end the St John Ambulance is often sent to the site of confrontation, occasionally at considerable personal risk to St John personnel. However, one cannot realistically foresee that the characteristically long evacuation time will cease to be an unfortunate feature of the Intifada.

Key words: Eye trauma, Intifada, Rubber/plastic bullets, Surgery.

\section{REFERENCES}

1. Jaouni ZM, O'Shea JG. Civilian eye casualties in East Jerusalem and the occupied territories. Medicine, Conflict and Survival 1996;12:138-48.
2. Hunter FA. The Palestinian uprising: a war by other means. London: IB Tauris, 1991:142-5.

3. Melman Y, Raviv D. Behind the uprising: Israelis, Jordanians and Palestinians. Westport, Conn.: Greenwood Press, 1989:1-15.

4. Playfair E (ed.). International law and the administration of occupied territories. Oxford: Clarendon Press, 1992: 1-85, 241-93, 443-57, 461-504.

5. Elder M. Penetrating eye injuries in children in the West Bank and Gaza Strip. Eye 1993;7:429-32.

6. Balouris CA. Rubber and plastic bullet injuries in Palestine. Lancet 1990;335:415.

7. Cohen MA. Plastic bullet injury to the face and jaws. S Afr Med J 1985;68:849-52.

8. Millar R, Rutherford WH, Johnson S, Malhotra VJ. Injuries caused by rubber bullets: a report on 90 patients. Br J Surg 1977;14:199-202.

9. Rocke L. Injuries caused by plastic bullets compared to those caused by rubber bullets. Lancet 1983;1:919-20.

10. Atmaca LS, Yilmaz M. Changes in the fundus caused by blunt ocular trauma. Ann Ophthalmol 1993;25: 447-52.

11. O'Shea JG. Before and after: the contribution of ocular prosthetics at St John Jerusalem. The St John National (Australia) 1994;12 (May):3-4.

12. Koval $\mathrm{R}$ et al. The Israeli Ocular Injuries Study: A nationwide collaborative study. Arch Ophthalmol 1988;106:776-80.

13. Thylefors B. Epidemiological patterns of ocular trauma. Aust NZ J Ophthalmol 1992;20:95-8.

14. Parver LM, Dannenberg AL, Blacklow B, Fowler CJ, Brechner RJ, Tielsch JM. Characteristics and causes of penetrating eye injuries reported to the National Eye Trauma System Registry, 1985-91. Public Health Rep 1993;108:11-23.

15. Dannenberg AL, Parver LM, Fowler CJ. Penetrating eye injuries related to assault. The National Eye Trauma System Registry. Arch Ophthalmol 1992; 110:849-52.

16. Scott R. British military surgery. J Trauma 1988; 8:S83-5. 